\title{
Features of the Information and Communication Technology Application by the Subjects of Special Education
}

\author{
Svetlana Vladimirovna Arhipova ${ }^{1} \&$ Olesya Sergeevna Sergeeva ${ }^{1}$ \\ ${ }^{1}$ Mordovian State Pedagogical Institute Named After M.E. Evseviev, Russia \\ Correspondence: Svetlana Vladimirovna Arhipova, Mordovian State Pedagogical Institute Named After M.E. \\ Evseviev, Saransk, Mordovia 430007, Russia.
}

Received: October 2, 2014 Accepted: November 16, 2014 Online Published: May 28, 2015

doi:10.5539/ies.v8n6p162 URL: http://dx.doi.org/10.5539/ies.v8n6p162

\begin{abstract}
The main purpose of this study is to reveal the features of information and communication technologies application by the subjects of education in the conditions of special (correctional) school type VIII, and to identify the level of computer literacy of special education. The study was conducted on the basis of the State Budgetary Special (Correctional) Educational Institution of the Republic of Mordovia (SBS(C) EI RM) for the students and pupils with disabilities in the "Saransk special (correctional) general education school Type VIII", Saransk (Russia). During the experiment, each group of respondents (teachers, students with intellectual disabilities and their parents) was offered the specially developed questionnaires. The assessment of responses was made by the following criteria: completeness of elementary computer skills the subjects possess; proficiency in computer programs and electronic products; degree of independence and the frequency of their application in practice. The results show us that the computer literacy of subjects is low. During the study we revealed that the use of modern information technologies is associated with certain difficulties, associated not only with the deficiency of computer and special software, but also with a low level of knowledge and skills of work on a personal computer among the subjects of special education.
\end{abstract}

Keywords: information and communications technologies, special education, electronic learning resources, computer literacy, subjects of special education, children with disabilities

\section{Introduction}

In the age of a fast changing world, constant development and complication of technology, the informatization of our education system has a fundamental importance (Xiaobin, 2013). Its intensive development based on the use of information and communication technologies (ICT) is becoming the most important national priority, including the field of Special Education within the Russian Federation (The RF Presidential Decree "On the National Strategy of Action for Children for the years 2012-2017"; Federal Target Program "The development of United Educational Information Environment" (dated August 28, 2001). The inclusion of ICT into the educational process has become a socially determined necessity that is conducive to increasing the accessibility and quality of training, and the development of personality, for those who surf freely on the information space.

The pedagogical accompaniment system of a child with limited possibilities of health (LPH) assumes the development of content, tools, and methods of the educational process, aimed at revealing and using the subjective experience of the student, disclosing his ways of thinking, forming the individual developmental trajectories through the educational program implementation in view of his personal needs (Khokhlova, 2011). The advantages of the same information technology as compared to other means include the possibility of training individualization, providing to every pupil with the LPH an appropriate pace, volume and ways of knowledge mastery and performance.

It is clear that information technology for children with LPH should take into account their special educational needs, which are determined by the specific patterns of deviant development: a slower rate of the age development, a general decline in mental activity, the inconsistency in the figurative and verbal areas of the psyche. Slow speed of receiving and processing of incoming information affects the underdevelopment of all forms of the objective activity. Disadvantages of verbal mediation and mental activity on the whole lead to deformation of the social situation of the child's development (Sergeeva \& Arkhipova, 2013). 
The studies of foreign scholars on the use of ICT in the educational process convincingly prove the possibility and expediency of their application in the development of speech, intelligence and personality of the student (Florian \& Hegarty, 2004; Fu, 2013; Maddux \& Johnson, 2009). The psychological and pedagogical aspects of the computer technologies application during the formation of worldview, elementary mathematical concepts, and the development of reading activity, self-written speech and communication skills in the children with the LPH received wide coverage (Kukushkina et al., 2004; Nikolskaya \& Podvalnaya, 2010).

However, in the special education system there are a number of difficulties, associated both with the lack of carefully designed and proven techniques for using ICT, and with insufficient levels of computer literacy, necessary to make an informed and productive application of information technologies (Williams, 2000; Wong et al., 2008). To the foreground the acuteness of outlined problems brings the study issues on the features of the information and communication technologies application by the subjects of education, and the determination of their level of computer literacy.

In the materials of this article, we discuss the results of our study on the features of the information and communication technologies application by the subjects of education in conditions of special (correctional) school Type VIII. This type of school is focused on the training and education of children with intellectual disabilities in order to correct deviations in their development by the means of education and job training, as well as social and psychological rehabilitation for subsequent integration into society.

\section{Methodology}

The methodological basis of the research which generalized results are principles of homocentric subject-subjective and person-centered approach to education (Bondarevskaya, Gavrilin, Novikova, Rogers, etc.); activity approach to the study of pedagogical processes and phenomena (Ananev, Vygotsky, Leontiev, Rubinstein and others); works devoted to various aspects of education informatization (Gershunsky, Rakitov, Ursul and others); research on problems of the computerization of special education (Florian, Kukushkin, Korolevskaya, Goncharova, Hegarty, Rogers and others); works devoted to didactic and methodological aspects of the formation of computer literacy of special education persons (Forostenko, Glazkova, Williams, Coles, Wilson, Richardson and others).

In our study, the information and communication technology education is a system of methods, techniques, tools to create pedagogical conditions on the basis of computer equipment, telecommunications equipment and interactive software that simulate some of the functions of the teacher on the submission, transmission and collection of information, organization and control of cognitive activity of students.

After analyzing a number of scientific research (Polat, Bukharkina, Moiseeva, Petrov and others) there have been marked out some areas of the use of ICT in the educational process (Polat, 2000).

Motivational direction in which the use of information technology increases the interest and formation of positive motivation of students, since favourable conditions for the individualization of the learning process were created.

Meaningful direction that allows using ICT abilities for development of individual test mini-lessons or for creating interactive homework and simulators for independent student work.

Educational and methodical direction in which electronic and information resources can be used as a training and methodological support of educational process.

Organizational direction allows using ICT for teaching each student on an individual program based on an individual plan and with front or subgroup forms of work.

Control and evaluation direction in which the primary means of control and evaluation of educational outcomes of students are tests and test tasks, which allow carrying out the various types of controls: initial, intermediate and final. Tests can be conducted on-line (on a computer in interactive mode, the result is evaluated automatically by the system) and off-line (evaluation of the results made by teachers with comments, correction of mistakes).

Use of information technology in the process of teaching of junior students with LPH is not only objective, but also quite natural process. On the one hand, information technologies are among the effective means to achieve the greatest possible success in the development of a child with special educational needs (Bondarenko, Vinogradova, Kukushkina, Nikolskaya and others). On the other hand, as shown in studies of Williams, Coles, Wilson, Richardson, Tuson and others, they help to prepare the student for the quick perception and processing of rapid flow of information and to equip him with modern tools and technologies of work, form the culture of information, namely: develop the ability of students to orient oneself in the information flows of the surrounding 
world; improve the ability of students to acquire practical and invariant ways of work with different kinds of information; form the skills to communicate with the help of modern technical means; develop the ability to make optimal decisions or offer variants of solution in a difficult situation using situational computer games aimed at optimizing the decisional behavior.

Traditionally, the major indicators of the success level of education of junior students with LPH are their ability to read, write and count. But in modern society, a new criterion has become urgent, i.e. computer literacy. By "computer literacy" we mean the minimum knowledge and skills of work at the personal computer. In general, the structure of this criterion can be represented by two blocks: the theoretical knowledge and practical skills. It's not just about the volume of information for learning, but also about the development of the ability of special education persons to search, store, process, analyze, transform, distribute this information, i.e. the development of their information competence.

Based on research of Glazkova, we marked out three directions of familiarization to the basics of computer literacy in terms of primary school:

1) Information in the surrounding world: information in a person's life, examples of information objects (text, numeric, graphic, audio), sources of information, ethics of information, etc.;

2) Work with information: transmission, search, conversion, storage;

3) Practice of work on the computer: the main purpose of computer devices, the rules of behavior and safety measures, the ability to work with information objects visually represented on the screen using the mouse and keyboard, work with simple data objects (text, audio, tables, images, typesetting, image design) (Glazkova, 2007).

Under incipient mass introduction of computer technology in a special school and its active use in all academic subjects, skills, constituting computer literacy, acquire general educational nature, leading to an intensification of the entire educational process.

\section{Results}

To analyze the state of the problem of information and communication technology use by persons of special education and to identify their level of computer literacy, surveys were conducted among the three groups of respondents: teachers, students and their parents. Respondents were offered questionnaires of closed, open and mixed types, specially designed for each group of respondents.

Questioning of students was conducted in a familiar environment, i.e. in the classroom. To provide individual work and to eliminate the influence of the respondents on each other, they were placed at separate desks, and the experimenter saw to it that the students did not share information during box-ticking. All questions were read by the experimenter, if necessary, they were explained and repeated. Questioning of teachers and parents carried out in free form: respondents answered the questions at home in their own time.

Analysis of the results of the first group of respondents-students-showed that only $33.3 \%$ have a computer at home, while $8.3 \%$ use it every day, and the remaining $25 \%-1-2$ times a week. Only $8.3 \%$ of fourth-graders with LPH have access to the Internet. It should be noted that the main purpose of using a computer at home is the play through of various computer games: from elementary children flash games ("Pet", "Winx", "Spider-Man", etc.) to full-grown computer simulators («Need for Speed», «Football», etc.) and 3D-shooters ("Assassin", "Shrek" and others).

$41.7 \%$ of students have simple skills of work with the program MS Word (typing and basic editing). They also have a minimum experience of using a graphic editor Paint. However, all the students who participated in the survey indicated the need for assistance from adults when working at the computer.

At school students do not work alone at the computer, but they note that teacher often uses it in during lessons. More than half of fourth-graders indicate that the most interesting and memorable tasks are made by them with the use of multimedia presentations. For $66.7 \%$ of the respondents the use of audio and video material is a factor that activates attention and stimulates the process of memorizing the study material. It should be noted that neither the educational computer games or educational software or interactive simulators were not named by students that indicates the absence of such in the educational process. And this is despite the fact that all of the respondents would like to use the computer and computer media in the process of learning more often.

As the results of our questioning of special school teachers showed, only half of the classrooms are equipped with computers, which naturally affect the frequency of its use. One group of teachers, who have free access to ICT at the workplace, noted that they try to apply computer technology at every lesson. At the same time they 
named the limited range of used computer means: multimedia presentations ( $80 \%$ of respondents), audio and video materials ( $40 \%$ of respondents), and specialized software ( $20 \%$ of respondents). Another group indicated that the opportunity to use the computer in the classroom is provided to them no more than once a month due to lack of free access to computer technology. However, more than half of the surveyed teachers $(70 \%)$ reported consistent use of Internet resources in preparation for lessons.

During questioning teachers identified difficulties that they have in preparing and conducting lessons with the use of computer technology. Responses of teachers are presented in Figure 1.

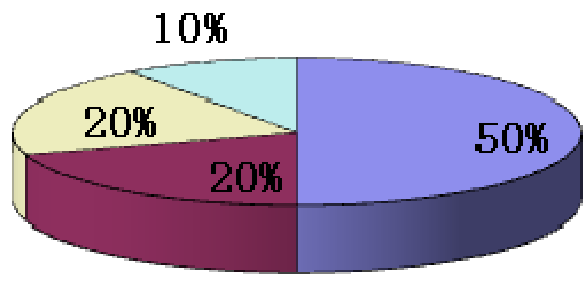

\begin{tabular}{|l|}
\hline 口lack of technical support \\
口lack of specialized \\
computer programs \\
alow level of computer \\
literacy of pupils \\
low level of computer \\
literacy of teachers
\end{tabular}

Figure 1. Problems of applying the computer technology in the process of pedagogical accompaniment of younger pupils with the HIA (on the results of teachers' survey)

The study revealed that the standard computer programs (MS Word, MS Excel, Power Point and others) allow the most active teachers themselves creating the elementary computer products for the younger pupils the LPH, because there are no certified electronic teaching aids, teaching software, and test-simulators equipping the educational process for the special institutions. The commercially available electronic products of specialized software, such as "The world behind your window" (Goncharova, Korolevskaya, and Kukushkina), "Mathematics for those who has problems: composition of number" (Bolshikh and Kukushkina), "Composition of a word" (Goncharova, Kukushkina, and Fedosova), and etc., are purchased by some teachers themselves.

The teachers were also asked to characterize their professional readiness to use the computer technologies in teaching children with the LPH and the proficiency in the generally available computer programs. The study showed that only $40 \%$ of teachers have the skills of using the computer tools and, consequently are ready to use them in the process of pedagogical accompaniment of pupils with the LPH; $50 \%$ of respondents have the elementary computer skills, but find it difficult to apply it in the process of teaching pupils with the LPH; $10 \%$ of teachers have no even elementary computer skills and are not ready to use it in their work.

The analysis of computer competence of teachers in the special (correctional) schools Type VIII showed that the majority of them feel their unpreparedness for the working with the publicly available computer programs (Figure 2). Moreover, the percentage of teachers, who do not have even the initial skills of using the separate programs, reaches $20 \%$. It should be noted that the level of computer literacy does not depend on the age or qualification category of teachers.

Using the questionnaires, we were trying to find out, whether the teachers pay attention to the formation of elementary computer knowledge and skills in the students with the LPH. The answer was unanimous: "No". In addition, the majority of respondents $(90 \%)$ don't see either the possibility or the necessity of carrying out such work with the younger pupils with the LPH. 


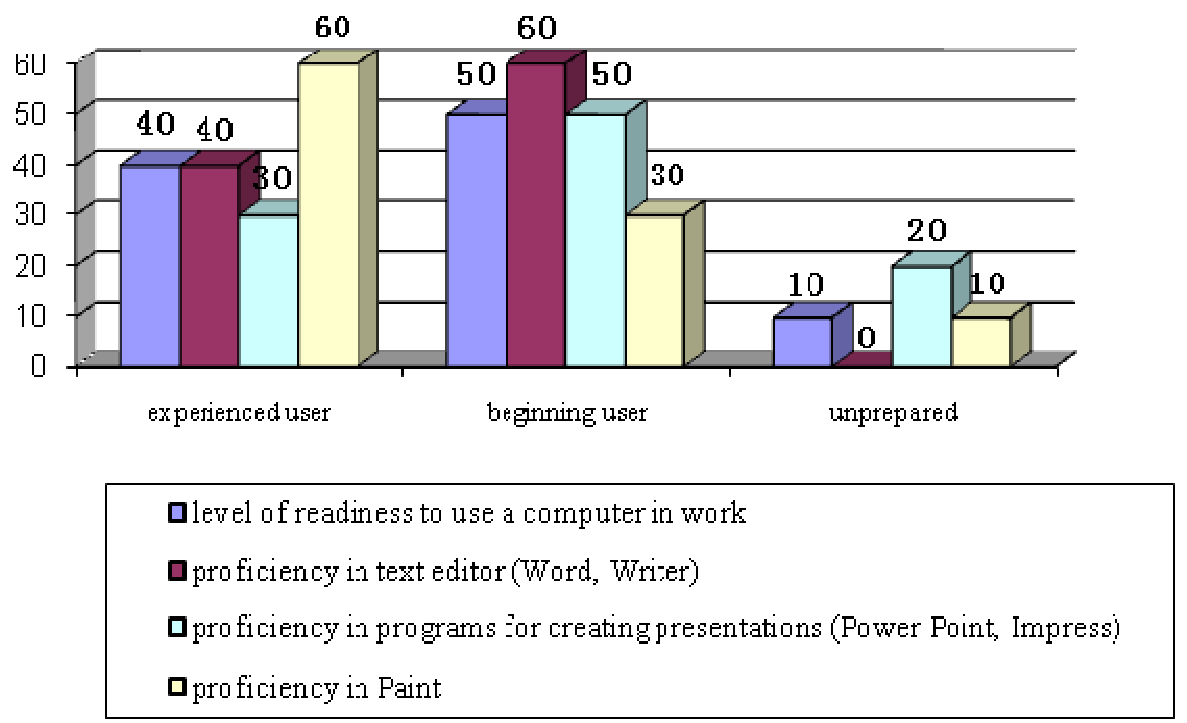

Figure 2. Distribution of teachers by the proficiency levels in publicly available computer programs (on the survey results)

Despite the fact that the necessity of using the information technologies in the educational process doesn't cause doubts among the respondents, there is no clear idea about the possibilities of their application. The lack of elementary computer equipment in the special schools makes difficult the formation of teachers' professional skills in this field. At the same time, the teachers' computer competence development is one of the conditions for the effective implementation of modern information technologies in the practice of educational institutions.

The questionnaire survey of the third group of respondents-parents-has revealed even the lower rates in the field of computer skills and the proficiency in computer programs (Figure 3). More than half of respondents (60\%) admitted in the complete absence of computer experience, and no more than $30 \%$ of parents pointed the presence of elementary skills to use the general computer programs.

Such results can be explained not only by the absence of home computer in the greater part of respondents (40\%), but also by its poor use: to search the information on the Internet $(10 \%)$, to communicate in social networks $(20 \%)$, to play computer games $(20 \%)$.

Only $20 \%$ of parents work at a computer with the child, but and that "work" is reduced mainly to help in the passage of computer games, which don't have a cognitive or developmental nature. 


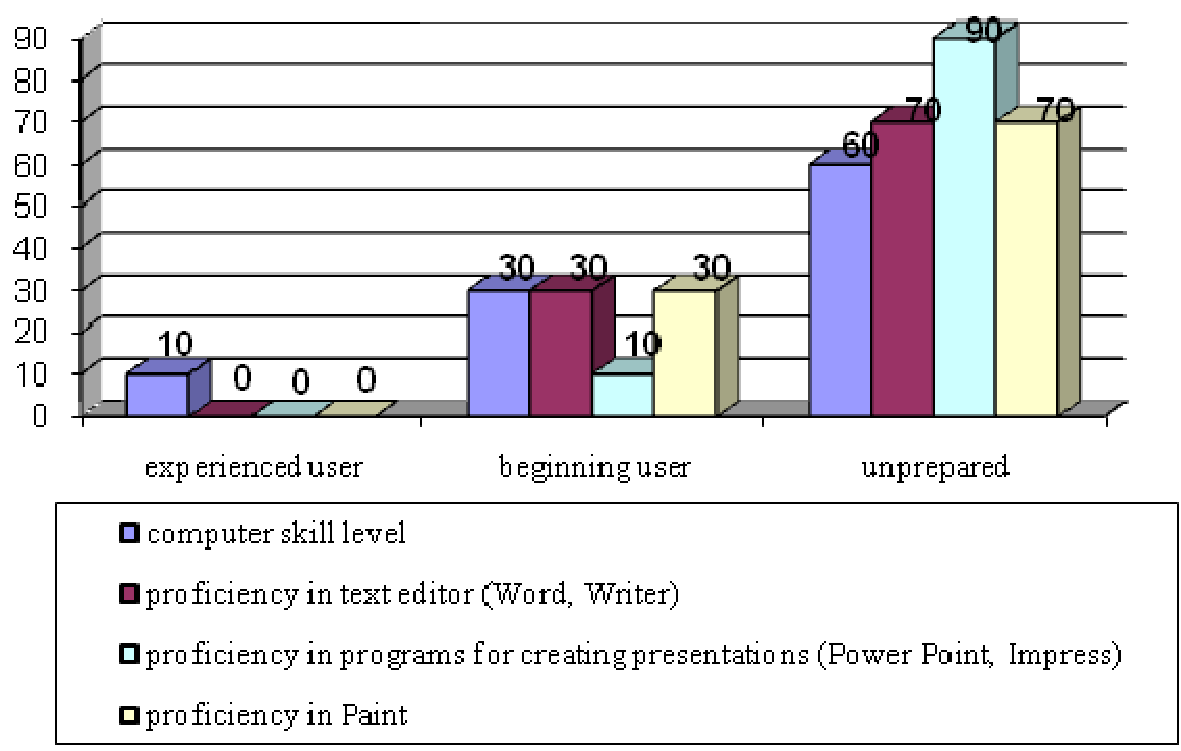

Figure 3. Distribution of parents by the proficiency levels in publicly available computer programs (on the survey results)

The most of respondents $(90 \%)$ is not satisfied with the level of computer literacy of their child, but at the same time, parents don't recognize the fact that they themselves are able to influence on its increase. The parents impute the full responsibility for the formation of computer literacy skills in pupils to the teachers of special school $(80 \%)$. At the same time, the respondents almost unanimously $(90 \%)$ speak in favor of greater use of computer means in the educational process.

The results of the study let us to divide the respondents in each category into three differentiated groups by the level of formed computer literacy (Figure 4).

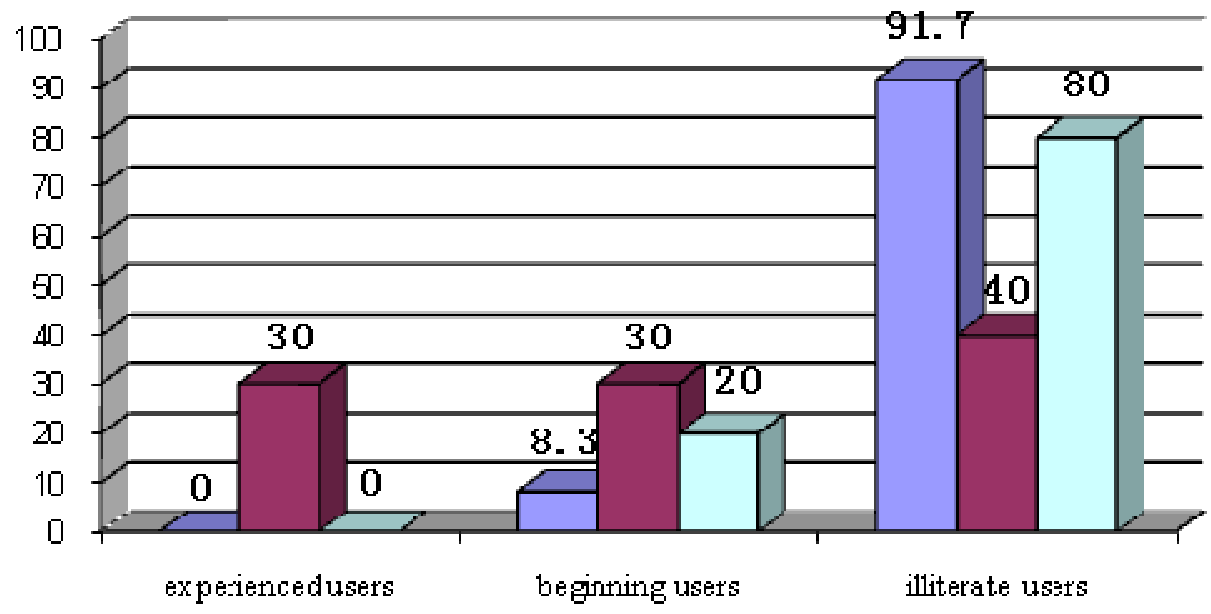

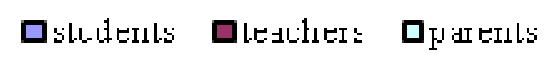

Figure 4. Quantitative distribution of respondents by results of study

The first group (students- $0 \%$; teachers-30\% parents- $0 \%$ )-is the "experienced users" who have a high level of development of elementary computer knowledge and skills. They were easily oriented through the 
questionnaire's questions, had a clear idea about the computer organization, and pointed a proficiency in the computer programs (Word, Power Point, Paint, etc.) and used the computer terminology accurately, when answering the open type questions. They demonstrated the independence and appropriate frequency of using the computer knowledge in practice.

The second group (students-8.3\%; teachers-30\% parents-20\%)-is the "beginning users", who have an average level of development of elementary computer knowledge and skills. They missed some questions in the questionnaire due to the partial lack of theoretical knowledge or misunderstanding of tasks, had inaccurate ideas about the computer organization. They realized their insufficient proficiency in the computer and computer programs, were the subject to inaccuracy using the specialized terminology when answering the open type questions. The subjects pointed out the necessity of outside assistance related to the computer use.

The third group (students-91.7\%; teachers-40\%; parents-80\%)-is the "illiterate users", have a low level of development of elementary computer knowledge and skills, missed the most of the questions in the questionnaire. Their answers didn't contain the constructive decisions on the proposed tasks, answers to the open type questions were given incorrectly, "by guess-work". The made the very gross errors using the computer terminology or its ignorance. They had the insufficient experience of working with computer and the lack of skills in using the commonly occurring computer programs (Word, Power Point, Paint, and etc.). The subjects pointed out the necessity of a constant assistance related to the computer use.

The data in Figure 4 shows us that in the first group-“experienced users"-only the respondents from the number of teachers are presented. There was no evidence of students and parents with a high level of computer literacy. In the group of "beginning users" there are the representatives of each subjects' category. Thus the number of teachers, who have reached this level, exceeds the number of parents in 1.5 times, and pupils-more than in 3 times. The third group-"illiterate users"-was the most numerous, where the quantitative indices among the students and parents are almost equal and exceed data among the teachers in 2 times.

\section{Discussion}

The results of our study suggest that the computer literacy of all subjects of special education is low. To date, the special school still doesn't have a free access to the modern information technologies, required for such organization of quality pedagogical accompaniment as: educational resources online; electronic educational resources, which extend the capabilities of educational environment and create the conditions for the creative thinking development of pupils; specialized software (developing and training games, tests, interactive simulators, and etc.).

The introduction of ICT in the special education is a necessity dictated by the current state of society development (Sergeeva \& Arkhipova, 2013; Norwich, 2008; Kraayenoord, 2007). The increase of computer literacy level of subjects in the educational process will lead to the modernization of the whole educational system, increasing its efficiency and quality, deepening the interdisciplinary communication through the use of modern means of filing, receiving and processing information (Forostenko, 2012; Glazkova, 2007).

The computer technologies not only allow developing the pupils with the LPH, but also prepare them for the independent and fulfilling life in the information society, creating a kind of link in the integration process, which connects that category of children with the surrounding world (Bryant, 2008; Rogers, 2013). The implementation of capabilities of modern information technologies extends the range of training activities types, allows improving the existing and gives rise to the new organizational forms and methods of pedagogical accompaniment. The use of modern information technologies contributes to solve one of the main tasks of correctional education-the development of pupil's individuality, his abilities to navigate and adapt in the modern society (Watson, 2001; Wegerif \& Dawes, 2004). This proves once again the necessity of overcoming all the difficulties in the use of ICT in the special education, relating to, among other things, the insufficient level of proficiency in computer technologies.

\section{Conclusion}

The global informatization process of all spheres of society is the leading factor, which causes the necessity to introduce the information technologies in the educational system, including the process of training of younger pupils with the LPH. The increased interest of society and state in this category of children actualizes the problem of increasing the efficiency of their integration into the environment of normally developing peers, in particular by using the information technologies as a means of their pedagogical accompaniment. Putting it together, it can be argued that the problem of using the ICT by the subjects of special education has its own features. On the one hand, a poor technical and material equipment of school doesn't allows you to involve the 
modern computer technologies fully, and the methods of their application needs to be improved, taking into account the specificity of children in this category. On the other hand, the lack of computer literacy of teachers, students and their parents greatly complicates the implementation of information technologies in the educational process.

\section{Acknowledgements}

This article was prepared with the financial support of the RF Ministry of Education and Science paid by the project 2.1 "The development of fundamental and applied researches and R\&D for the humanitarian directions of science and education" of the Strategic Development Program of MordGPI for 2012-2016 years.

\section{References}

Bryant, D. (2008). Infusing a teacher preparation program in learning disabilities with assistive technology. Journal of Learning Disabilities, 31(5), 55-66.

Federal Target Program "The development of United Educational Information Environment" (by the RF Government Resolution \# 630 dated August 28, 2001). Education in documents, 9, 15-19.

Florian, L., \& Hegarty, J. (2004). ICT and Special Educational Needs: A Tool for Inclusion. Open University Press.

Forostenko, E. (2012). Computer literacy as a socialization means of pupils with the mild mental retardation. Retrieved from www.nsportal.ru/shkola/sotsialnaya-pedagogika/library/metodicheskaya-rabota-kompyutern a-ya-gramotnost-kak-sredstvo

Fu, F. (2013). ICT in Education: A Critical Literature Review and Its Implications. International Journal of Education and Development using Information and Communication Technology, 1(9), 12-18.

Glazkova, N. (2007). The problem of developing the information literacy of students with the intelligence nondevelopment. Proceedings of the Russian State Ped. University named after A.I. Herzen, 7, 69-72.

Khokhlova, N. (2011). Psychological and educational support for children with disabilities in the integrated education process. Defectology, 6, 20-24.

Kraayenoord, C. (2007). School and classroom practices in inclusive education in Australia. Childhood Education, 83(6), 390-394. http://dx.doi.org/10.1080/00094056.2007.10522957

Kukushkina, O. (2004). How to make visible the hidden problems in child development. M.: Poligraph.

Maddux, C., \& Johnson, D. (2009). Information technology in education: The need for a critical examination of popular assumptions. Computers in the Schools, 26(1), 1-3. http://dx.doi.org/10.1080/07380560802688232

Nikolskaya, I. (2010). Information technologies application in the education of children with disabilities. Modern child and educational space: Problems and Ways of Implementation: Proceedings of the All-Russian Scientific and Practical Conference. Novokuznetsk: RIO KuzGPA.

Norwich, B. (2008). Dilemmas of difference, inclusion and disability. Routledge.

Polat, E. (2000). New pedagogical and Information technologies in the education system: Handbook for the students of Ped. Universities and the career development system of pedagogical personnel. M.: Academy.

Rogers, C. (2013). Inclusive education and intellectual disability: a sociological engagement with Martha Nussbaum. International Journal of Inclusive Education, 17(9), 988-1002. http://dx.doi.org/10.1080/13603116.2012.727476

Sergeeva, O. (2013). Interactive simulator as a tool for improving the teaching mathematics process of students with intellectual disabilities. Humanitary Sciences and Education, 3, 77-81.

Watson, D. (2001). Pedagogy before Technology: Re-thinking the Relationship between ICT and Teaching. Education and Information Technologies, 4(6), 251-266. http://dx.doi.org/10.1023/A:1012976702296

Wegerif, R., \& Dawes, L. (2004). Developing Thinking and Learning with ICT: Raising Achievement in Primary Classrooms. RoutledgeFalmer.

Williams, D., Coles L., Wilson K., Richardson, A., \& Tuson, J. (2000). Teachers and ICT: Current use and future needs. British Journal of Educational Technology, 31(4), 307-320. http://dx.doi.org/10.1111/1467-8535.00164

Wong, E., Li, S., Choi, T., \& Lee, L. (2008). Insights into Innovative Classroom Practices with ICT: Identifying the Impetus for Change. Educational Technology \& Society, 1(11), 20-26. 
Xiaobin, L. (2013). Information and Communication Technology in Education: Getting Chinese Connected for Learning. International Journal of Information and Communication Technology Education (IJICTE), 1(9), $1-11$.

\section{Copyrights}

Copyright for this article is retained by the author(s), with first publication rights granted to the journal.

This is an open-access article distributed under the terms and conditions of the Creative Commons Attribution license (http://creativecommons.org/licenses/by/3.0/). 